\title{
Editorial
}

\section{Management of Neck Pain}

\author{
Joy C. MacDermid ${ }^{*}, \S$
}

\begin{abstract}
School of Rehabilitation Science, McMaster University, Hamilton, Ontario and Clinical Research Lab, Hand and Upper Limb Centre, St. Joseph's Health Centre, London, Ontario, Canada
\end{abstract}

The focus of this special issue is evidence-informed management of neck pain. Neck pain is an important issue since the majority of individuals will experience it at some point in their lifetime. Many cases of neck pain resolve so some might consider neck pain to be a minor inconvenience. However, in reality many cases of neck pain are episodic and cause substantial interference with work and quality of life during painful periods. Furthermore, a subset of people have chronic neck pain and disability that contribute to ongoing or permanent pain and disability. The percentage of people who experience chronic neck pain and disability varies according to the study, context and type of individuals evaluated. Regardless of which study is cited, the fact remains that many people are affected by neck pain and a subset of these will experience severe ongoing problems. This underlies the importance for evidence-informed management to ensure that patients receive the best treatment and outcomes and that healthcare systems are not overly burdened with ineffective practices.

Due to the importance of neck pain, a group of investigators submitted a knowledge synthesis grant to The Canadian Institutes of Health Research (CIHR) to bring together best evidence around management of neck pain. Through this grant, the investigators engaged a wide group of international collaborators who are experts in the area of neck pain management. The International Collaboration on Neck (ICON) group (noted below) provided critical contributions throughout the development of the grant, conduct of the work and in dealing with the challenges that arose in conducting overviews on different areas of clinical management of neck pain. Hence, they are authors on most of the papers in this journal.

Although most people would agree that an evidenceinformed approach to neck management is ideal, accomplishing it is difficult. There are many limitations related to the clinical science foundations that contribute to this difficulty [1]. Clinicians need to engage research information to integrate evidence-informed decision-making for musculoskeletal disorders throughout the components of the clinical interaction that occurs in their daily practice.

\footnotetext{
*Address correspondence to this author at the School of Rehabilitation Science, McMaster University, 1400 Main St. West, IAHS-403, Hamilton, ON L8S 1C7, Canada; Tel: 905-525-9140, Ext. 22524; Fax: 905-524-0069; E-mail: macderj@mcmaster.ca

${ }^{\S}$ Guest Editor
}

During a clinical interaction, clinicians often start with diagnosis and classification, then move on to think about treatment selection and any potential harms that might arise from it. As part of the joint decision-making with patients, the benefits and harms of treatment must be discussed along with the prognosis for specific outcomes. Clinicians use prognostic information in guiding management, patient expectations, monitoring recovery and long-term planning for resumption of usual life roles. Finally, clinicians select outcome measures to monitor the important aspects of the presenting problem and use these to monitor recovery. The types of studies and evidence that support these different clinical functions vary. Evidence-informed recommendations for management must consider these different types of studies if a comprehensive view of management is to be provided. The studies published in this special issue address all of these aspects of the clinical interaction.

Diagnosis and classification of musculoskeletal injuries, disorders or syndromes is a critical first step in establishing proper management. Despite this, there are no clear diagnostic tests which can establish specific pathologies or structural abnormalities in most cases of neck pain. Furthermore, the classification of neck pain is in its infancy, since rudimentary classifications that have made a minor contribution to advancing our management of neck pain are all that is available to most clinicians. The overview mapping the evidence available on neck pain indicated minimal high quality evidence to support these two aspects of the clinical interaction.

Typically, in a clinical interaction, once the cause of the presenting complaint is diagnosed or classified, a clinician will move on to consider what treatments might be best suited for that particular patient and any potential harms that would arise from that. Clinicians wanting to use the evidence to inform their decision-making for neck pain are fortunate to find an ever increasing amount of evidence addressing neck pain. However, this increasing volume-often with conflicting findings - of evidence is part of the challenge in itself. Systematic reviews are often used to synthesize evidence on a given topic to make more definitive conclusions. Systematic reviews can be very useful to clinicians as they mitigate the need for reading multiple RCTs to select a treatment approach. There are many different systematic reviews that focus on neck pain-some taking a comprehensive approach and others looking at isolated treatments. In fact, the volume of systematic reviews on neck pain presents a substantial burden on clinicians, 
particularly when systematic reviews provide conflicting results. Therefore, this special issue highlights a number of overviews. Overviews or reviews of (systematic) reviews synthesize systematic reviews in a structured way to provide a more comprehensive summary of the state of knowledge on a specific topic. The advantage of this approach is that it can bring together information across multiple systematic reviews. However, the methodology is challenging and less clearly defined than a systematic review or meta-analysis. The authors of reviews in this special issue started with a common approach to collecting the evidence (Santaguida et $a l$.), but had to customize the synthesis in different types of overviews based on the number and type of reviews that were found. The overview methodology paper presents the approach, but each overview presented in this special issue discusses the challenges unique to different types of evidence about management of neck pain. For example, while there is a rich body of knowledge addressing treatment effectiveness with respect to neck pain, the pool of evidence addressing prognosis and outcome evaluation is quite shallow.

The prognostic overview provides useful information on the state of evidence on prognosis (Walton et al.), and highlights the deficiencies in current prognostic systematic reviews or meta-analyses and the primary studies upon which they are based. One of the most enlightening findings of this overview was the diversity of findings in existing systematic reviews. This highlights the challenges for clinicians who rely on systematic reviews to give "best practice", since conflicting reviews can cause a substantial problem to clinicians trying to implement evidence-based practice. The prognostic overview also highlighted the challenges in conducting a review of systematic reviews when there are problems in the underlying evidence, and for this reason the ICON group and international co-authors were critical partners in making choices about "making the best" of the available evidence.

Evidence-informed decision-making relies on the three pinnacles of evidence-based practice: clinical expertise, patient preferences and the best evidence. For this reason, we felt it was important to establish practice patterns in the management of neck pain. A number of the papers in this special issue are surveys of clinical practice to establish these practice patterns. These clinical practice surveys were able to indicate areas where practice is well aligned with the evidence, and other areas where there is substantial variation or even a disconnect between the evidence and practice. Establishing practice patterns can be a critical step in understanding where research or knowledge translation is needed.

Finally, the third piece of the triad that supports evidence-informed decision-making is patient preferences. Understanding the patient perspective can occur during individual interactions between the patient and the clinician. However, qualitative research is also important since it brings a level of rigor to the understanding of the issues. In this special issue, qualitative papers describe the patient's perspective on receiving healthcare for neck pain and explore the meaning of recovery. One of the themes raised in these qualitative studies was the challenges that patients experience in maintaining activity in the presence of neck pain and its exacerbations. One of the individual studies published in this special issue addresses the issue of activity in patients with neck pain in a quantitative analysis.

This special issue brings together a large volume of evidence that can be applied to management of neck pain. It also highlights that much work remains to be done.

ICON is a multi-disciplinary collaborative group that includes scientist-authors (listed below) and support staff (Margaret Lomotan) that conduct knowledge synthesis and translation aimed at reducing the burden of neck pain.

The ICON scientist-authors are (in alphabetical order): Gert Bronfort, Norm Buckley, Lisa Carlesso, Linda Carroll, Pierre Côté, Jeanette Ezzo, Paulo Ferreira, Tim Flynn, Charlie Goldsmith, Anita Gross, Ted Haines, Jan Hartvigsen, Wayne Hing, Gwendolen Jull, Faith Kaplan, Ron Kaplan, Helge Kasch, Justin Kenardy, Per Kjær, Janet Lowcock, Joy MacDermid, Jordan Miller, Margareta Nordin, Paul Peloso, Jan Pool, Duncan Reid, Sidney Rubinstein, P. Lina Santaguida, Anne Söderlund, Natalie Spearing, Michele Sterling, Grace Szeto, Robert Teasell, Arianne Verhagen, David M. Walton, Marc White.

\section{REFERENCES}

[1] MacDermid JC, Gross AR, Galea V, et al. Developing biologically-based assessment tools for physical therapy management of neck pain. J Orthop Sports Phys Ther 2009; 39(5): 388-99.

(c) Joy C. MacDermid; Licensee Bentham Open.

This is an open access article licensed under the terms of the Creative Commons Attribution Non-Commercial License (http://creativecommons.org/licenses/by-nc/3.0/) which permits unrestricted, non-commercial use, distribution and reproduction in any medium, provided the work is properly cited. 